\title{
Hereditary Vesicoureteral Reflux: A Study of 66 Families
}

\author{
Zsuzsa I. Bartik1, Agneta Nordenskjöld², Sofia Sjöström¹, Rune Sixt1, Ulla Sillén1 \\ ${ }^{1}$ The Pediatric Uro-Nephrologic Centre, The Queen Silvia Children's Hospital, Sahlgrenska Academy, University \\ of Gothenburg, Gothenburg, Sweden \\ ${ }^{2}$ Department of Women and Children Health, Karolinska Institutet and Center of Molecular Medicine, \\ Karolinska University Hospital, Stockholm, Sweden \\ Email: zsuzsa.bartik@vgregion.se
}

Received 9 September 2015; accepted 29 November 2015; published 2 December 2015

Copyright (C) 2015 by authors and Scientific Research Publishing Inc.

This work is licensed under the Creative Commons Attribution International License (CC BY). http://creativecommons.org/licenses/by/4.0/

(c) (i) Open Access

\section{Abstract}

Purpose: We studied the inheritance pattern, clinical features and outcome in children with vesicoureteral reflux (VUR). Characteristics of known familial VUR cases were also compared with those of sporadic VUR. Material and Methods: 726 patients were treated for VUR between 19902004. The families were contacted by letter inquiring if other members of the family were affected. The phenotype of all cases (familial and non-familial) was characterized in terms of presenting symptoms, reflux grade, recurrent urinary tract infections, kidney damage, and the natural course of reflux. Results: The response rate was $79 \%$. A total of 99 individuals $(22 \%)$ reported relatives with VUR. Since some of the 99 index cases belonged to the same family, the total number of families was ultimately 66 . The distribution of relatives with VUR was: 38 siblings, 20 parents (15 mothers), 19 cousins, 15 aunts/uncles and 12 grandparents. The phenotype of VUR did not differ between familial and non-familial cases. However, VUR among relatives was of milder grade than index and sporadic cases. Conclusions: The proportion of hereditary reflux in our material was lower than in other studies $(\mathbf{2 2} \%)$. We found a strong overrepresentation of maternal transmission of reflux. Severity of the disease did not differ between familial and non-familial VUR.

\section{Keywords}

Vesicoureteral Reflux, Heredity, Phenotype

\section{Introduction}

Vesicoureteral reflux (VUR) is a common abnormality affecting $1 \%-2 \%$ of the pediatric population [1]. The 
association between VUR and urinary tract infection (UTI) is well known, with risk for scarring of the renal parenchyma. Several studies have shown familial clustering of VUR, implying that genetic factors play an important role in its pathogenesis. For example, siblings of children with VUR are at higher risk of reflux than the general population, with reported prevalences between 27\% and 51\% [2]-[4]. Among multiple gestation births the concordance is higher in monozygotic twins than in dizygotic ones ( $80 \%$ vs. 35\%) [5]. Moreover, the risk for offspring of parents with previously diagnosed VUR of having VUR themselves is reported to be $66 \%$ [6].

Although subjects with VUR may present with similar initial symptoms, some cases have a benign natural course with no recurrent UTIs, no progressive renal damage and a high rate of spontaneous resolution of the reflux. Others, on the other hand, have recurrent UTIs, deterioration of renal status and persistent reflux [7]. These two phenotypes may have different etiological and genetic backgrounds. Therefore, it is of great interest to establish whether this previously described inherited (familial) form of VUR represents the same disease as the sporadic cases (when only one individual in the family has VUR) or whether it has a more aggressive course. In order to answer this question we assessed clinical features including severity of reflux, frequency of recurrent infections, renal damage, overall kidney function, and natural course in familial VUR compared with sporadic reflux cases. The aim of this study was to increase the understanding of the etiology of VUR. This knowledge can be further used to predict prognosis and individually tailor appropriate treatment.

\section{Material and Methods}

Figure 1 illustrates the data selection process for the study. Seven hundred and twenty-six children with VUR

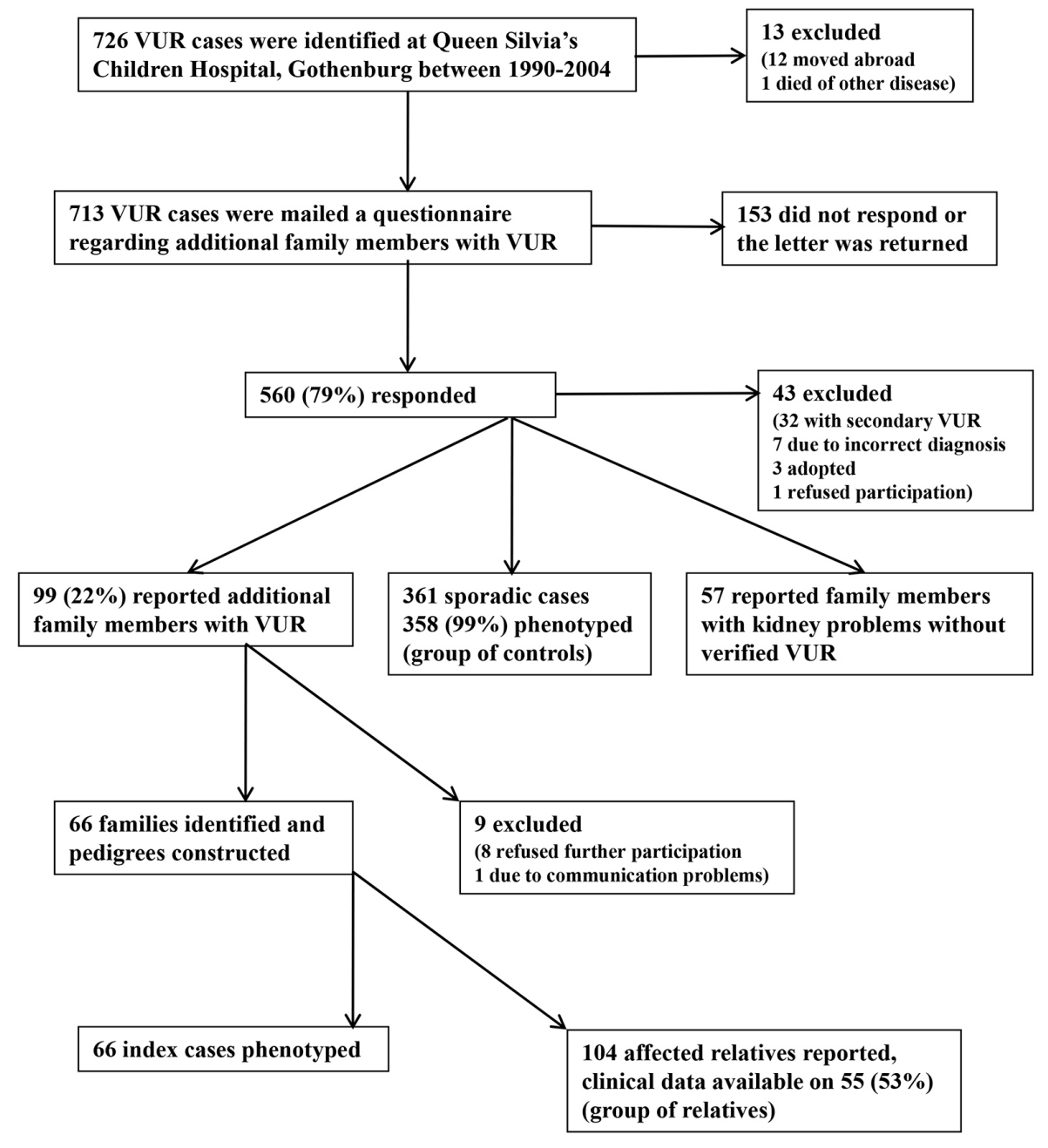

Figure 1. Flow chart showing the collection of cases. VUR = Vesicoureteral reflux. 
treated at Queen Silvia’s Children Hospital (a tertiary referral center) in Gothenburg, Sweden between 1990 and 2004 were identified through medical records. Letters were sent to all but 13 index cases, inquiring as to whether there were other members of the family or close relatives with VUR. The 99 cases that reported more than one individual with VUR were interviewed by telephone. During this conversation we inquired as to which members of the family had diagnosed VUR or had symptoms indicating such a problem, i.e. recurrent UTIs, bladder function symptoms or kidney problems. We also asked about possible consanguinity in the family. In this study, familial VUR cases were defined as patients with one or more first, second or third degree relatives with VUR. These affected relatives were analyzed as a separate group and compared with index and non-familial cases. Patients with VUR secondary to urethral valves, myelomeningocele or high anal atresia with neurogenic bladder were excluded from the study.

For inclusion of family members in the group of relatives with VUR, a previously performed voiding cystourethrography (VCU) showing reflux was mandatory, except for older relatives diagnosed in an era when VCU was not in general use. A history of recurrent febrile UTIs during childhood with or without renal damage suggesting high probability for VUR was accepted in these cases. Relatives with radiologically confirmed diagnosis were marked as certain VUR cases in the pedigrees $(n=55)$, while cases with a strong history but with no radiological investigations available were labelled probable affected cases $(n=49)$ (Figure 2). Fifty-seven index patients who reported other members of the family with vague history of diffuse urinary tract problems, such as cystitis during adulthood, were excluded.

Owing to the fact that some individuals with VUR in our material belonged to the same family, the total number of families with hereditary reflux was ultimately 66. These 66 families were invited to participate in our study, and informed consent from patients and family members was obtained to examine medical records regarding their VUR and kidney status. The families were also asked to provide blood samples for a genetic study [8].

To clarify the relationship and analyse the pattern of inheritance, pedigrees were constructed for each family. VUR in all affected individuals was characterised regarding presenting symptoms, grade of reflux, recurrent UTIs, kidney damage, natural course of the reflux, surgical treatment and additional anomalies. Data was also collected from medical records on subjects who did not report any relatives with VUR (controls), a total of 361 individuals. In these patients we recorded presenting symptoms, grade of reflux at presentation, recurrent UTIs (yes or no) and renal damage.

When recording the recurrent UTIs, only the febrile infections $\left(>38.5^{\circ} \mathrm{C}\right)$ with positive urinary culture (at least $100,000 \mathrm{cfu} / \mathrm{ml}$ ) were counted in the hereditary groups. In the group of controls such data about symptoms and urinary culture were not always available.

In the characterisation of the subjects, grade of reflux was registered from VCU investigations according to the international grading system, both at presentation and at the latest follow-up before eventual surgical treatment [9]. In case of bilateral VUR, the patient was classified by the more severe side. Resolution of VUR was defined as grade II or less. DMSA and MAG-3 scintigraphy results were used for evaluation of renal damage, including split function, parenchymal abnormalities and size of kidneys. Focal damage was defined as one or more areas with reduced uptake or indentation of the renal outline. Generalised damage was classified as a small kidney with reduced tracer uptake or diffuse parenchymal anomaly. Reference values for split function were between $45 \%$ and 55\%. Usually more than one scintigraphy was performed during the follow-up time. In this study we present the results from the latest available investigations regarding renal abnormality.

Glomerular filtration rate (GFR) was assessed using 51Cr-EDTA. In the cases where no direct GFR measurement was available, indirect GFR estimation was performed according to the formula of Schwartz [10] from serum creatinine and the height $(\mathrm{cm})$ of the patient. The reference value used for normal GFR was $110 \mathrm{mmol} / \mathrm{l} /$ $1.73 \mathrm{~m}^{2}$ after two years of age according to Bröchner-Mortensen [11] and GFR $<80 \%$ (<2SD) of expected GFR was considered subnormal. Before two years of age, steady state of GFR is not achieved, and for this age group we operationally used the equation developed by Winberg for estimation of expected clearance [12]. Deterioration of renal status at follow up was defined as loss of $\geq 7 \%$ of split function seen on scintigram or decrease of GFR with $\geq 12 \%$.

Statistical methods. In the statistical analysis of VUR phenotype in the group of relatives, only the 55 cases (of 104) were included, i.e. those who had performed VCU, whereas in the index and control groups VCU was performed in all cases and thus included. For categorical variables $n$ (\%) is presented, and for continuous variables Median (Min-Max). For comparisons between groups the chi-square test was used for non-ordered categorical variables, while Kruskal-Wallis test was used for continuous variables. For pairwise comparison be- 

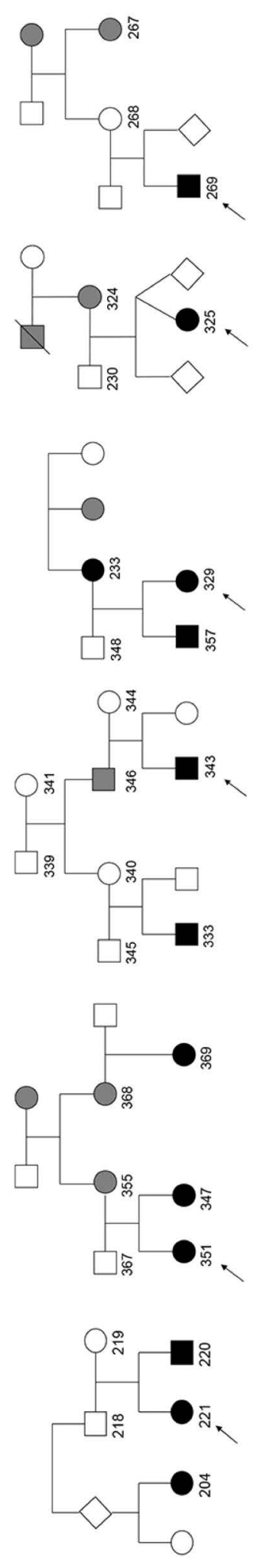
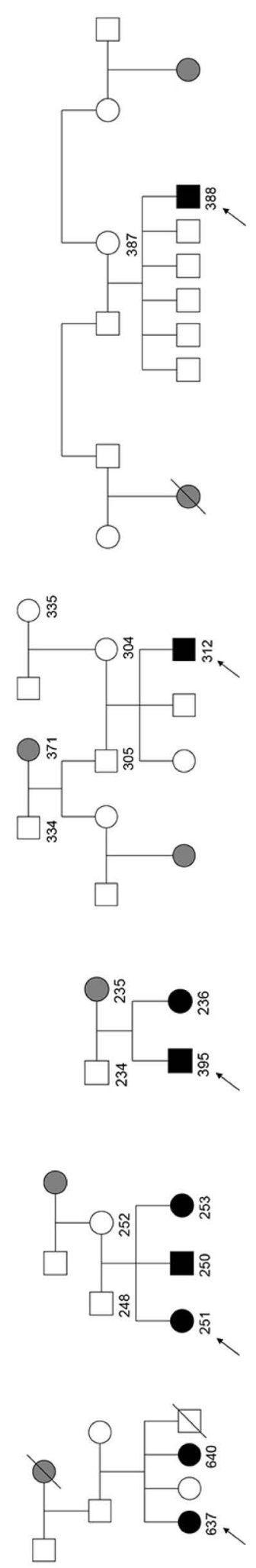
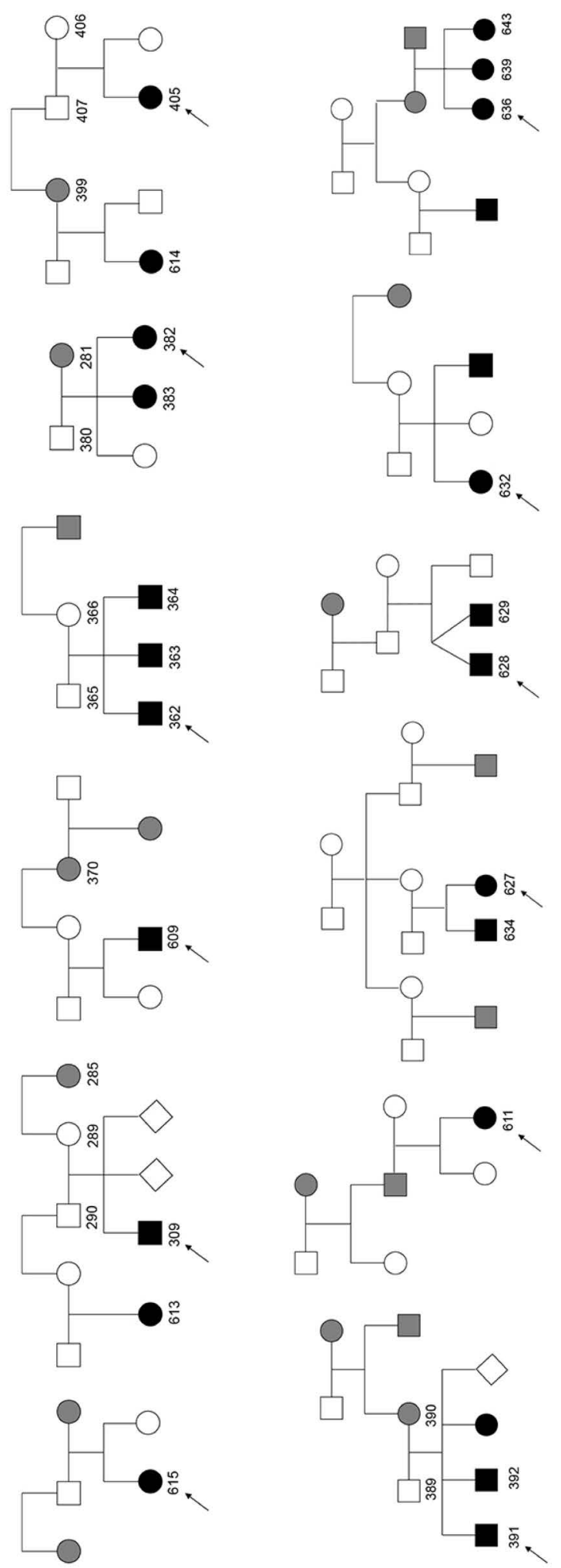
tween groups, Fisher's exact test was used for dichotomous variables, Mantel-Haenszel chi-square test was used for ordered categorical variables, chi-square test was used for non-ordered categorical variables and MannWhitney U-test for continuous variables. All tests were 2-tailed and conducted at the $5 \%$ significance level.

Approval from the Regional Ethical Review Board in Gothenburg was obtained

\section{Results}

\subsection{Familial Aggregation}

The response rate of the VUR patients to the questionnaire regarding relatives with VUR was $79 \%$ (560 of 713 subjects). Of 560 individuals with VUR, 99 reported additional family members, 361 reported no relatives with VUR and 57 reported diffuse urinary tract problems in family members but without diagnosed reflux. Since it was uncertain whether or not individuals in this latter group had hereditary reflux, they were excluded. Thus, 22\% (99/460) had relatives with reflux.

Some of these 99 index cases belonged to the same family and therefore the total number of families with hereditary reflux was ultimately 66 . The distribution of relatives with a history of VUR including both confirmed and probable affected cases was: 38 siblings, 20 parents (15 of whom were mothers), 19 cousins and second cousins, 15 aunts/uncles and 12 grandparents (Table 1). The proportion of girls among siblings and cousins was 22/38 (58\%) and 10/17 (59\%) respectively, which does not differ from the proportion in the entire material (58\%).

The numbers of affected members in the families are shown in Table 2. 25/66 (38\%) families had three or more affected members, whereas 41 only had two. In this latter group with 2 affected individuals, 21 of 41 were sibs. In total, VUR was inherited from the mother's family in 25 cases while paternal inheritance was seen in 15 cases. In four cases the families of both parents were affected and in one case sufficient data was missing. Pedigrees are shown for subjects with three or more affected family members (Figure 2).

\subsection{Phenotype of Familial and Non-Familial VUR}

For analysis the material was divided into index patients $(n=66)$, relatives with confirmed VUR $(n=55)$ and controls $(n=358)$. The results are presented in Table 3. There was overrepresentation of females in all three groups, with no significant difference between the groups. The presenting symptom was pyelonephritis in the majority of cases. However, VUR in relatives had been detected to a significantly higher extent by pre- or postnatal screening than in index cases and controls. Fourteen of 52 (27\%) relatives were diagnosed by screening in comparison with only 2 of 65 (3\%) index patients and 25 of $342(7 \%)$ controls $(\mathrm{p}<0.0001)$. Nine of the 14 screened

Table 1. Sixty-six families with hereditary VUR; relationship between 66 index cases and 104 affected relatives.

\begin{tabular}{cc}
\hline Affected relatives & Number (\%) \\
\hline Siblings & $38(37)$ \\
Parents & $20(19)$ \\
Grandparents & $12(12)$ \\
Aunts/uncles & $15(14)$ \\
Cousins/second cousins & $19(18)$ \\
Total number (\%) & $104(100)$ \\
\hline
\end{tabular}

Table 2. Sixty-six families with hereditary VUR; number of affected subjects per family and maternal/parental transmission.

\begin{tabular}{ccccc}
\hline No. of VUR patients/family & No. of families & Maternal transmission & Paternal transmission & Unknown transmission \\
\hline 2 affected/family & 41 & 12 & 7 & 1 unknown side, 21 only sibs \\
3 affected/family & 18 & 7 & & 3 both sides \\
4 affected/family & 4 & 4 & & 1 both sides \\
5 affected/family & 3 & 2 & 15 & 26 \\
6 affected/family & 66 & 25 & & \\
Total number & & & \\
\hline
\end{tabular}


Table 3. Dermographic data, VUR grades, renal abnormalities and function split by hereditary (index and relatives) and non-hereditary (controls) VUR.

\begin{tabular}{|c|c|c|c|c|c|c|}
\hline \multirow{3}{*}{ Variable } & \multirow{3}{*}{$\begin{array}{l}\text { Index } \\
\mathrm{n}=66\end{array}$} & \multirow{3}{*}{$\begin{array}{c}\text { Relatives } \\
\text { n = 55 }\end{array}$} & \multirow{3}{*}{$\begin{array}{l}\text { Controls } \\
\mathrm{n}=358\end{array}$} & \multicolumn{3}{|c|}{ Test between groups } \\
\hline & & & & \multicolumn{3}{|c|}{ p-value } \\
\hline & & & & Index vs relatives & Index vs controls & Relatives vs controls \\
\hline \multicolumn{7}{|l|}{ Sex } \\
\hline Female & 38 (58\%) & 37 (67\%) & $201(56 \%)$ & & & \\
\hline Male & $28(42 \%)$ & $18(33 \%)$ & 157 (44\%) & 0.365 & 0.925 & 0.152 \\
\hline \multicolumn{7}{|l|}{ Presenting symptom VUR } \\
\hline Pyelonephritis & $61(94 \%)$ & $36(69 \%)$ & 308 (90\%) & & & \\
\hline Pre- and postnatal screening & $2(3 \%)$ & $14(27 \%)$ & $25(7 \%)$ & & & \\
\hline Other symptoms & $2(3 \%)$ & $2(4 \%)$ & $9(3 \%)$ & 0.001 & 0.449 & $<0.0001$ \\
\hline Age at presentation (months) & $8(0.1-84)$ & $7.0(0.1$ - 98) & $8(0-141)$ & 0.674 & 0.637 & 0.893 \\
\hline \multicolumn{7}{|l|}{ Grade of reflux } \\
\hline I & $2(3 \%)$ & $4(8 \%)$ & $9(3 \%)$ & & & \\
\hline II & $7(11 \%)$ & $11(23 \%)$ & $42(12 \%)$ & & & \\
\hline III & $21(32 \%)$ & $22(45 \%)$ & $123(34 \%)$ & & & \\
\hline IV & $24(36 \%)$ & $8(16 \%)$ & 140 (39\%) & & & \\
\hline $\mathrm{V}$ & $12(18 \%)$ & $4(8 \%)$ & $44(12 \%)$ & 0.002 & 0.436 & 0.0003 \\
\hline \multicolumn{7}{|l|}{ Grade of reflux at follow up } \\
\hline 0 - II & $18(32 \%)$ & $18(47 \%)$ & & & & \\
\hline III - V & 38 (68\%) & 18 (53\%) & & 0.136 & & \\
\hline \multicolumn{7}{|l|}{ Recurrent UTIs } \\
\hline No & 27 (44\%) & $20(47 \%)$ & $168(50 \%)$ & & & \\
\hline Yes & 35 (56\%) & 23 (53\%) & $171(50 \%)$ & 0.919 & 0.465 & 0.831 \\
\hline \multicolumn{7}{|l|}{ Renal abnormality } \\
\hline No & $18(28 \%)$ & $13(36 \%)$ & $90(26 \%)$ & & & \\
\hline Yes & 46 (72\%) & $23(64 \%)$ & 255 (74\%) & 0.543 & 0.840 & 0.276 \\
\hline \multicolumn{7}{|l|}{ Total renal function } \\
\hline Normal & $50(82 \%)$ & $34(79 \%)$ & 226 (87\%) & & & \\
\hline Subnormal & $11(18 \%)$ & $9(21 \%)$ & 33 (13\%) & 0.900 & 0.378 & 0.235 \\
\hline
\end{tabular}

relatives were examined due to reflux in sibling. Age at presentation was median 8 months (range: 0 - 141), with no difference between the groups.

\subsection{VUR Grade}

The grade of reflux at presentation was significantly lower among the relatives than the index patients $(p=0.002)$ and the same was seen for relatives vs. controls $(p=0.0003)$ (Table 3, Figure 3$)$. The grades of reflux in both the index and control groups showed the same distribution. Bilateral reflux was more common than unilateral reflux, with no differences between the groups. The rate of resolution of VUR was only analyzed in the hereditary groups. The reflux resolved spontaneously in 18 of 56 (32\%) in the index group and 18 of $36(50 \%)$ in the group with relatives but the difference did not reach significance. The follow-up time was median 32 months (range: 5 - 117) counting the last VCU prior to eventual surgical treatment. However, persistent VUR was corrected surgically significantly more often in index cases than in relatives $(\mathrm{p}=0.034)$.

\subsection{Urinary Tract Infection}

The number of individuals with recurrent UTIs was high, with no difference between the groups (56\%, 53\% and 
$50 \%$ in index, relatives and controls, respectively) (Table 3).

\subsection{Renal Status}

The number of children with renal damage was similarly high in all three groups. Forty-six of $64(72 \%)$ in the index group, 23 of 36 (64\%) in the group with relatives and 255 of $345(74 \%)$ in the control group showed renal abnormalities (Table 3). Focal damage was seen in 22 of 64 (34\%) index patients, 5 of 36 (14\%) relatives and 101 of 345 (29\%) controls, whereas generalized damage was present in 23 of 64 (36\%) in the index group, 18 of $36(50 \%)$ in the group with relatives and 143 of $345(42 \%)$ of controls $(\mathrm{p}=0.284)$ (Figure 4). Most of the renal damage was unilateral, with no differences between the groups. After median 62 months (range: 4 - 233) of follow-up, very few individuals showed deterioration in renal status (4 of 44 (9\%) and 4 of 25 (16\%) in the index and relative groups, respectively).

GFR did not differ between the groups (median 92\%, 93\% and 98\% of normal, for the index, relatives and controls respectively). Furthermore, the number of individuals with subnormal GFR was also similar in index (11 of 61 (18\%)), relative (9 of 43, (21\%)) and control (33 of 253 (13\%)) (Table 3).

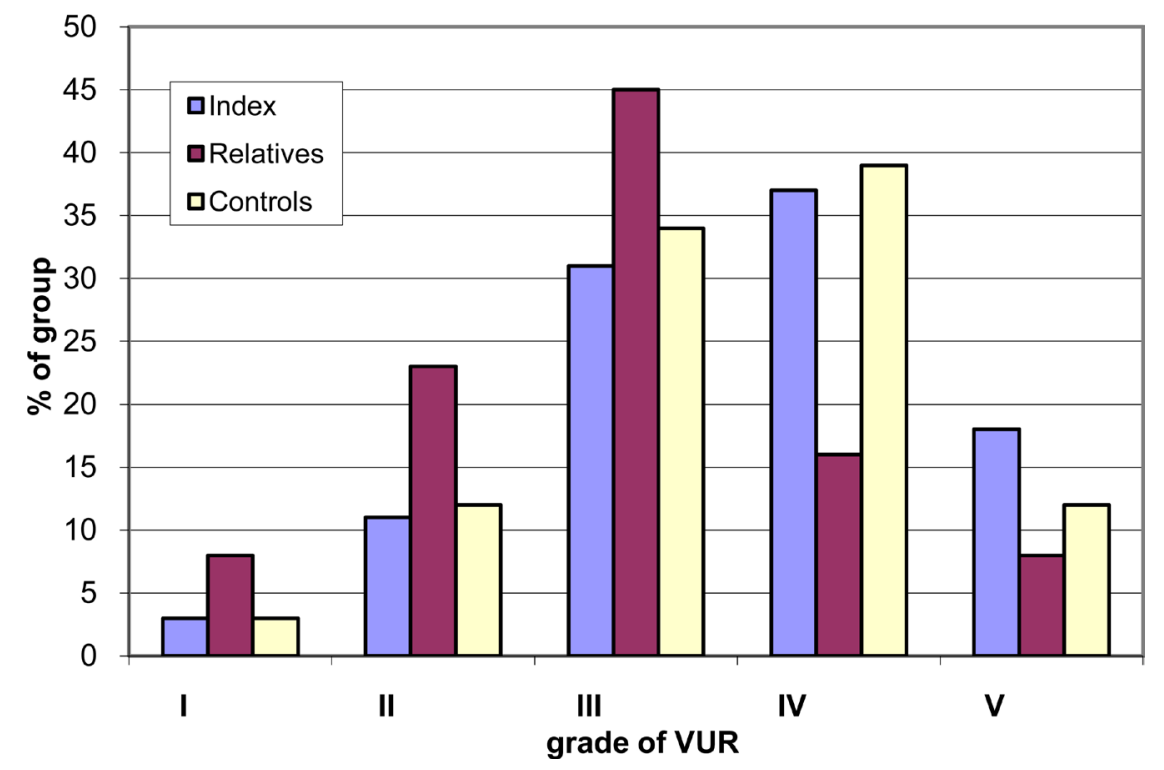

Figure 3. Grade of VUR according to study group, hereditary (index patients and relatives) and non-hereditary (controls).

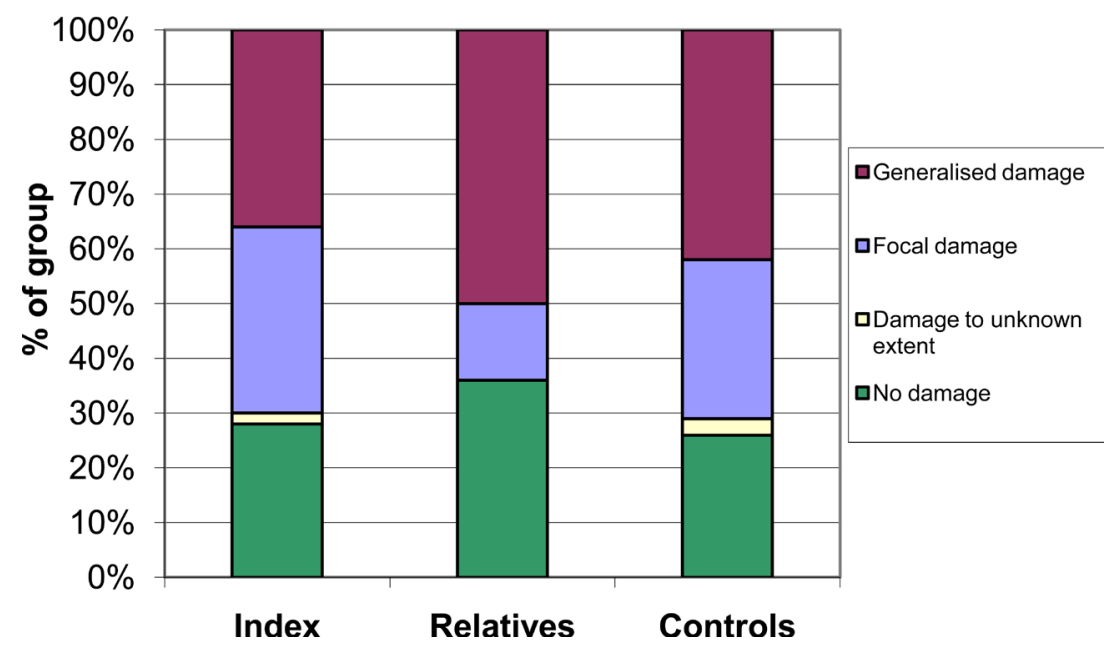

Figure 4. Prevalence of renal abnormality according to study group, hereditary (index patients and relatives) and non-hereditary (controls). 


\subsection{Additional Anomalies of the Urinary Tract (UT) and Other Organs}

In 50 of 66 (76\%) index cases and 44 of 55 (80\%) relatives, VUR was the only abnormality of the UT. The most common associated UT anomaly was duplex kidney, which was seen in $18 \%$ and $13 \%$ of cases in the index and relative groups, respectively. In 13 of 66 families (20\%) VUR could be a part of the CAKUT syndrome (congenital anomalies of the kidney and urinary tract) as duplex kidney or congenital generalised renal damage was seen in more than one family member. The majority of individuals in the two hereditary groups showed no anomalies in other organs (11/66 (17\%) and 3/55 (6\%) for index and relatives).

\section{Discussion}

Vesicoureteral reflux is a congenital defect of the urinary tract with a high risk of inheritance if a parent or sibling is affected. However, of the 560 individuals who responded to our questionnaire, 99 had other relatives with VUR while 361 had none. There was strong overrepresentation of maternal transmission of VUR. In 20 families, VUR was inherited from a parent, and in 15 of these 20 cases the inheritance was maternal. In addition, when all affected family members (except siblings) are taken into account, maternal inheritance was seen in 25 families and paternal inheritance in 15 cases. This overrepresentation of maternal inheritance has been noted in other studies but has not been attributed any particular significance [13]-[15]. One should be aware of selection bias when interpreting these results. One possible explanation in our study is that the questionnaire and the telephone interview were answered to a higher extent by the mothers of the index patients than the fathers, thereby reflecting the health problems of the maternal relatives to a higher degree. Scott et al. [15] put forward a similar explanation, rather than linkage to the X-chromosome, as suggested in a report describing a large family [16]. To date, no genetic study has confirmed the involvement of the X-chromosome in transmission of VUR. The maternal transmission of VUR could also be explained by imprinting mechanism.

The above discussed difference regarding inheritance of VUR versus gender can of course be associated with the fact that reflux is more often seen in females, in the present study 58\%. Another interesting difference regarding VUR in boys and girls is the reflux phenotype. In boys reflux is often diagnosed early during infancy, is high-grade and often with congenital generalised renal damage (hypo/dysplasia). In girls, on the other hand, the peak for diagnosis is between age 1 and 2 years, the reflux is of moderate or low grade and when renal damage is present it is often focal. Therefore, a gender-specific genetic difference may well be possible, which actually recently was shown in a study of sib-pairs with familial VUR: in males significant peaks were found on chromosome 1 and 5 and in females on 3, 13 and 15 [17].

However, VUR being a non-visible malformation in asymptomatic individuals and with a possible natural course of spontaneous resolution during childhood [18] [19] makes reflux a difficult abnormality to study in terms of heredity from one generation to another. Moreover, the fact that VCU is the only existing investigation for confirming the diagnosis leads to uncertainty in older generations, for whom this examination was not in common use. These relatives often report recurrent UTIs and problems associated with renal damage but there are no VCU films, either because no VCU was done or because the individual has forgotten.

When comparing the two study groups, familial and non-familial VUR, there were no significant differences in sex, presenting symptoms, severity of VUR, frequency of breakthrough infections, renal damage or total renal function. However, differences were noted within the hereditary group between the index group and the group with relatives. The relatives were more often diagnosed through screening than index patients (27\% vs 3\%). The 14 screened relatives were all siblings. Still, our study showed a low screening frequency as compared with other studies regarding hereditary VUR. The explanation for this difference is probably the method of confirming VUR diagnosis in relatives: in our study by questionnaire, hospital records and previous VCU films, whereas in most other studies VCU investigations of siblings were performed [3] [4] [20] [21].

Differences in grade of VUR were also noted between the index group and the group with relatives, with significantly lower grades in the latter group. The same relation has previously been shown in screened siblings of children with reflux [2] [4]. One might think that our results are mainly explained by low-grade reflux in the screened siblings. However, there was no difference in grade of VUR in the different relationships: siblings, parents, cousins and aunts/uncles in the group with relatives. Another possible explanation is an increased knowledge of VUR when there is a previous case in the family, leading to earlier diagnosis even without active screening.

Overall, the prevalence of renal damage was high in the total material (74\%), with no difference between the 
hereditary and the non-hereditary groups.In other materials comparing index patients with their refluxing siblings the prevalence of renal damage was 30\% [20]. The explanation for the difference is suggested to be the fact that fewer children with low-grade reflux are diagnosed and treated in Scandinavia. In fact, the frequency of renal damage found here is very similar to that found in a recent Swedish reflux trial [22]. Cascio et al. reported an increased number of cases with normal kidneys in the relatives as compared with both index and controls [23]. A simmilar relationship was detected in the present study but the difference was not significant. In addition a lower frequency of mild renal damage (focal) was reported by Menezes et al. in relatives without UTI as compared with both index patients and relatives with a history of UTI [20]. A similar tendency with lower number of relatives with focal damage was also seen in the present study.

Thus, the lower frequency of focal damage in relation to generalized damage in the relative group, as mentioned above, could theoretically be explained by lower frequency of recurrent febrile UTIs causing fewer new scars, which was reported in the study by Menezes et al. [20]. Even if we found in the present study that the VUR in the relative group was milder with regard to grade of VUR we saw no difference in incidence of infections between the groups. This could of course be explained by the low number of patients and difficulties in finding reliable data about UTI in older relatives.

Methodological limitations of our study was the lack of VCU in almost half of the relatives with VUR, owing to the fact that this radiological examination was not performed prior to the 1960s. In addition, relatives of patients with VUR were not routinely screened in Sweden, which could be responible for the lower prevalence of familial VUR in our material. Relatives with VUR could be underreported in both the herditary and control groups. The missed cases probably presented with less symptoms, given the availability of the Swedish health care. We agree that VCU is the gold standard method to detect VUR. However, it is a higly invasive investigation, which limits its use in asymptomatic relatives.

\section{Conclusion}

In conclusion, we found a possible increased inheritance of VUR via the mother, a result that is worthy of further examination both regarding inheritance and genetics. No difference was found between the phenotype of familial and non-familial reflux, whereas there was a difference between the index and relative groups, such as lower grade of reflux in the latter group.

\section{References}

[1] Amar, A.D. (1972) Familial Vesicoureteral Reflux. The Journal of Urology, 108, 969-971.

[2] Jerkins, G.R. and Noe, H.N. (1982) Familial Vesicoureteral Reflux: A Prospective Study. The Journal of Urology, 128, 774-778.

[3] Parekh, D.J., Pope, J.C.T., Adams, M.C. and Brock 3rd., J.W. (2002) Outcome of Sibling Vesicoureteral Reflux. The Journal of Urology, 167, 283-284. http://dx.doi.org/10.1016/S0022-5347(05)65450-X

[4] Wan, J., Greenfield, S.P., Ng, M., Zerin, M., Ritchey, M.L. and Bloom, D. (1996) Sibling Reflux: A Dual Center Retrospective Study. The Journal of Urology, 156, 677-679. http://dx.doi.org/10.1016/S0022-5347(01)65782-3

[5] Kaefer, M., Curran, M., Treves, S.T., Bauer, S., Hendren, W.H., Peters, C.A., Atala, A., Diamond, D. and Retik, A. (2000) Sibling Vesicoureteral Reflux in Multiple Gestation Births. Pediatrics, 105, 800-804. http://dx.doi.org/10.1542/peds.105.4.800

[6] Noe, H.N., Wyatt, R.J., Peeden Jr., J.N. and Rivas, M.L. (1992) The transmission of Vesicoureteral Reflux from Parent to Child. The Journal of Urology, 148, 1869-1871.

[7] Sjostrom, S., Sillen, U., Jodal, U., Sameby, L., Sixt, R. and Stokland, E. (2010) Predictive Factors for Resolution of Congenital High Grade Vesicoureteral Reflux in Infants: Results of Univariate and Multivariate Analyses. The Journal of Urology, 183, 1177-1184. http://dx.doi.org/10.1016/j.juro.2009.11.055

[8] Zu, S., Bartik, Z., Zhao, S., Sillen, U. and Nordenskjold, A. (2009) Mutations in the ROBO2 and SLIT2 Genes Are Rare Causes of Familial Vesico-Ureteral Reflux. Pediatric Nephrology, 24, 1501-1508. http://dx.doi.org/10.1007/s00467-009-1179-9

[9] Lebowitz, R.L., Olbing, H., Parkkulainen, K.V., Smellie, J.M. and Tamminen-Mobius, T.E. (1985) International System of Radiographic Grading of Vesicoureteric Reflux. International Reflux Study in Children. Pediatric Radiology, 15, 105-109. http://dx.doi.org/10.1007/BF02388714

[10] Schwartz, G.J., Brion, L.P. and Spitzer, A. (1987) The Use of pLasma Creatinine Concentration for Estimating 
Glomerular Filtration Rate in Infants, Children, and Adolescents. Pediatric Clinics of North America, 34, 571-590.

[11] Brochner-Mortensen, J., Haahr, J. and Christoffersen, J. (1974) A Simple Method for Accurate Assessment of the Glomerular Filtration Rate in Children. Scandinavian Journal of Clinical and Laboratory Investigation, 33, 140-143. http://dx.doi.org/10.3109/00365517409082481

[12] Winberg, J. (1959) The 24-Hour True Endogenous Creatinine Clearance in Infants and Children without Renal Disease. Acta Paediatrica, 48, 443-452.

[13] Conte, M.L., Bertoli-Avella, A.M., de Graaf, B.M., Punzo, F., Lama, G., La Manna, A., Grassia, C., Rambaldi, P.F., Oostra, B.A. and Perrotta, S. (2008) A Genome Search for Primary Vesicoureteral Reflux Shows Further Evidence for Genetic Heterogeneity. Pediatric Nephrology, 23, 587-595. http://dx.doi.org/10.1007/s00467-007-0675-Z

[14] Feather, S.A., Malcolm, S., Woolf, A.S., Wright, V., Blaydon, D., Reid, C.J., Flinter, F.A., Proesmans, W., Devriendt, K., Carter, J., Warwicker, P., Goodship, T.H. and Goodship, J.A. (2000) Primary, Nonsyndromic Vesicoureteric Reflux and Its Nephropathy Is Genetically Heterogeneous, with a Locus on Chromosome 1. American Journal of Human Genetics, 66, 1420-1425. http://dx.doi.org/10.1086/302864

[15] Scott, J.E., Swallow, V., Coulthard, M.G., Lambert, H.J. and Lee, R.E. (1997) Screening of Newborn Babies for Familial Ureteric Reflux. Lancet, 350, 396-400. http://dx.doi.org/10.1016/S0140-6736(97)01515-8

[16] Naseri, M., Ghiggeri, G.M., Caridi, G. and Abbaszadegan, M.R. (2010) Five Cases of Severe Vesico-Ureteric Reflux in a Family with an X-Linked Compatible Trait. Pediatric Nephrology, 25, 349-352. http://dx.doi.org/10.1007/s00467-009-1293-8

[17] Marchini, G.S., Onal, B., Guo, C.Y., Rowe, C.K., Kunkel, L., Bauer, S.B., Retik, A.B. and Nguyen, H.T. (2012) Genome Gender Diversity in Affected Sib-Pairs with Familial Vesico-Ureteric Reflux Identified by Single Nucleotide Polymorphism Linkage Analysis. BJU International, 109, 1709-1714. http://dx.doi.org/10.1111/j.1464-410X.2011.10634.x

[18] Esbjorner, E., Hansson, S. and Jakobsson, B. (2004) Management of Children with Dilating Vesico-Ureteric Reflux in Sweden. Acta Paediatrica, 93, 37-42. http://dx.doi.org/10.1111/j.1651-2227.2004.tb00671.x

[19] Sjostrom, S., Sillen, U., Bachelard, M., Hansson, S. and Stokland, E. (2004) Spontaneous Resolution of High Grade Infantile Vesicoureteral Reflux. The Journal of Urology, 172, 694-699. http://dx.doi.org/10.1097/01.ju.0000130747.89561.cf

[20] Menezes, M. and Puri, P. (2009) Familial Vesicoureteral Reflux-Is Screening Beneficial? The Journal of Urology, 182, 1673-1677. http://dx.doi.org/10.1016/j.juro.2009.02.087

[21] Noe, H.N. (1992) The Long-Term Results of Prospective Sibling Reflux Screening. The Journal of Urology, 148, 1739-1742.

[22] Brandstrom, P., Esbjorner, E., Herthelius, M., Holmdahl, G., Lackgren, G., Neveus, T., Sillen, U., Sixt, R., Sjoberg, I., Stokland, E., Jodal, U. and Hansson, S. (2010) The Swedish Reflux Trial in Children: I. Study Design and Study Population Characteristics. The Journal of Urology, 184, 274-279. http://dx.doi.org/10.1016/j.juro.2010.01.055

[23] Cascio, S., Yoneda, A., Chertin, B., Colhoun, E. and Puri, P. (2003) Renal Parenchymal Damage in Sibling Vesicoureteric Reflux. Acta Paediatrica, 92, 17-20. http://dx.doi.org/10.1111/j.1651-2227.2003.tb00462.x 